\title{
José Luis Sánchez y Luis Cubillo: entre el Románico y la Vanguardia
}

\author{
JESÚS GARCÍA HERRERO \\ Arquitecto. Profesor de Proyecto de Instalaciones. Escuela Técnica Superior de Arquitectura \\ Universidad Politécnica de Madrid \\ jesus.garciah@upm.es
}

\begin{abstract}
Resumen
La presente comunicación tiene su origen en una entrevista realizada al escultor José Luis Sánchez el 22 de diciembre de 2011, para conocer su aportación a la arquitectura religiosa de Luis Cubillo de Arteaga. El artista, que trabajó con más de un centenar de arquitectos, se convirtió en uno de los referentes del nuevo arte sacro, junto a Pablo Serrano, José Luis Alonso Coomonte o Venancio Blanco. Colaborador habitual de José Luis Fernández del Amo, compartía con él su visión integradora de las artes, frente a la primacía dada por Miguel Fisac a la arquitectura sobre la escultura y la pintura.

Las tres ocasiones en que trabajó con Cubillo, todas ellas en templos madrileños, permiten varias consideraciones sobre su obra, desde el citado diálogo con la arquitectura hasta las fuentes de inspiración de sus esculturas. Su primera colaboración se dio en la iglesia del Poblado Dirigido de Canillas (1962). La escultura del Crucificado que preside el templo remite al arte románico y su esencialización de la forma. Así mismo, se constata que la radical estética industrial del edificio de Cubillo necesitaba algo distinto de la imaginería de Olot dominante. Las obras realizadas en las parroquias de San Fernando (1973) y Jesús de Nazaret (1974), recogen con fidelidad las indicaciones del Concilio Vaticano II sobre el número de imágenes en el templo, así como la jerarquía que se debía establecer entre ellas. Especialmente destacables son los trabajos realizados en la primera. En ella, además de las imágenes, José Luis Sánchez diseñó todo el mobiliario litúrgico, desde los altares hasta los candelabros. La integración total con la arquitectura y el acertado manejo de materiales y texturas convierten su trabajo en este edificio en un buen exponente del arte socializante que el artista persiguió a lo largo de su obra.
\end{abstract}

Palabras clave: Románico, estética industrial, arte socializante, imágenes.

Arte y Ciudad - Revista de Investigación 


\title{
José Luis Sanchez and Luis Cubillo: between the romanesque and the avant-garde
}

\begin{abstract}
This communication comes from an interview done on December 22, 2011 to the sculptor José Luis Sánchez, to know his contribution to the religious architecture of Luis Cubillo de Arteaga. The artist, who worked with over a hundred architects, became one of the leaders of the new religious art, with Pablo Serrano, Jose Luis Alonso Coomonte or Venancio Blanco. Usual collaborator of José Luis Fernández del Amo, both them shared an inclusive vision of the arts, in opposition to the primacy given by Miguel Fisac to architecture.

The three times he collaborated with Cubillo, all in churches in Madrid, allow several considerations about his work, from said dialogue with the architecture, to the sources of inspiration for his sculptures. Their first collaboration was in the church of Canillas (1962). The sculpture of the Crucified who chairs the temple refers to Romanesque art and its essentialization of the form. It is also noted that the radical industrial aesthetic of Cubillo's building needed something different to the dominant imagery of Olot. The works in the parishes of San Fernando (1973) and Jesus of Nazareth (1974), are respectfull with the indications of Vatican II about the number of images in the temple, and the hierarchy that should be established between them. Especially remarkable is the work done in the first one. In it, in addition to the images, Jose Luis Sanchez designed the entire liturgical furniture, from the altar to the chandeliers. Full integration with the architecture and the successful handling of materials and textures became his work in a good exponent of sociali-sing art that the artist pursued throughout his work.
\end{abstract}

Key words: Romanesque, industrial aesthetic, socialising art, images.

La presente comunicación tiene su origen en una entrevista realizada al escultor José Luis Sánchez el 22 de diciembre de 2011, para conocer su aportación a la arquitectura religiosa de Luis Cubillo de Arteaga.

José Luis Sánchez propugnaba un cambio en la mentalidad de la sociedad española a través del arte contemporáneo. Para ello consideraba que se requería actuar en los centros de reunión de las personas, especialmente las iglesias y los colegios. En las primeras, los artistas comenzaron a introducirse 
de la mano de José Luis Fernández del Amo y sus pueblos de Colonización. Se alejaban así de la burguesía madrileña, poco receptiva a sus propuestas de vanguardia. Este matiz socializante de su obra, junto a la indudable ayuda económica que suponían los trabajos de encargo, convirtió a José Luis Sánchez en uno de los artistas españoles más fecundos del arte religioso en la segunda mitad del siglo XX, y referencia ineludible junto a Pablo Serrano, José Luis Alonso Coomonte o Venancio Blanco.

Intentábamos hacer un arte socializante, como el arte ruso pero en católico. El arte ruso se había parado en una forma de expresión y nosotros queríamos apurar más.

Así, José Luis Sánchez trabajó con más de un centenar de arquitectos a lo largo de su carrera. Las colaboraciones más frecuentes, según rememora el artista, fueron con José Luis Fernández del Amo, Javier Carvajal, Rodolfo García Pablos, Juan Manuel Ruiz de la Prada y Miguel Fisac.

Con el primero compartía su visión integradora de las artes, considerando que la relación óptima entre ellas sería la equivalente a la que se daba en un conjunto de música de cámara. Por el contrario, la posición de Fisac estaría más cercana a la de la orquesta dirigida por una batuta, la del arquitecto.

Con Luis Cubillo trabajó en tres templos madrileños: la iglesia del Poblado Dirigido de Canillas (anteproyecto de 1958) y las parroquias de San Fernando y de Jesús de Nazaret (proyectos de 1970 y 1972, respectivamente). En todos ellos las vidrieras fueron realizadas por Arcadio Blasco. Además también colaboró con el arquitecto en otros trabajos de arte no religioso, diseñando muebles o realizando un "Ícaro" para el concurso que la empresa Aviaco convocó en 1974. En Canillas, el escultor realizó una de sus obras más apreciadas: el Cristo que preside el presbiterio, que parece hacer suyas las palabras de Pablo Serrano:

La dominante de la cruz deben ser sus brazos, largos brazos. Nunca el hombre como hoy necesitó de amparo y comprensión, nunca como hoy necesitó del templo como sencilla y humilde casa, y esta casa-templo debe acoger y no sobrecoger (AMANN, 1965: IV).

En efecto, según José Luis Sánchez, se buscó un Cristo que abrazase, forzando la dimensión horizontal. La escultura fue realizada en hierro soldado, a excepción de la cabeza, que era de cemento. En opinión de Mª Teresa Gon- 
zález Vicario, su expresionismo y simplificación de formas se llevó a un extremo tal que el cuerpo de Jesucristo se convirtió en el símbolo de la cruz.

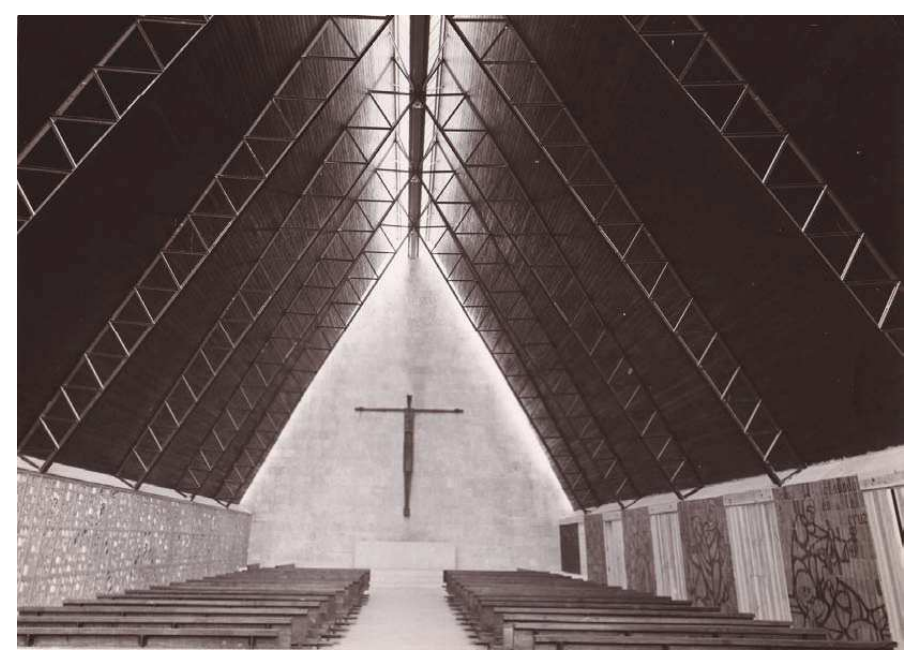

Fig. 1. Crucificado en la iglesia del Poblado Dirigido de Canillas, Madrid, 1962. Fuente: Archivo familia Cubillo.
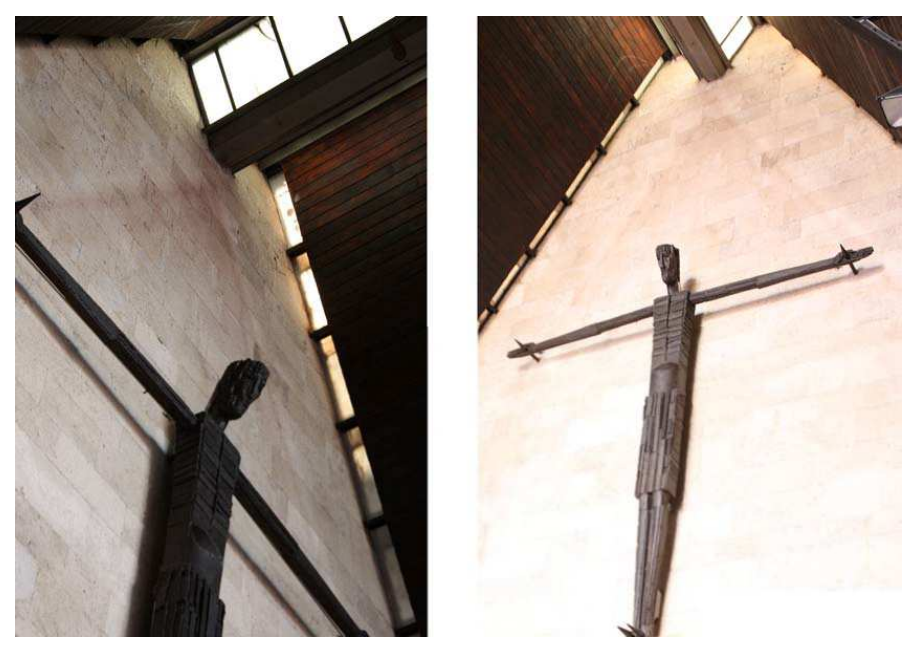

Figs. 2-3. Detalles del Crucificado en la iglesia del Poblado Dirigido de Canillas, Madrid, 1962.

A este respecto, el artista rememoraba que la radical arquitectura de la iglesia de Canillas no permitía cualquier tipo de escultura:

Para expresarnos con mayor libertad recurríamos a la vidriera, que transformaba un hangar en un templo, por medio del color, creando una atmósfera mágica, mística.... (La iglesia de Canillas) fue la más revolucionaria que se hizo en España....Yo luego he visto otras cosas en arquitecturas externas, nórdicas, pe- 
ro tenían el mismo espíritu. Si a esa arquitectura le ponías un Cristo "musculoso", era una cosa que no iba. Entonces también desaparecía esa cosa tan barroca que supone el individualismo de las capillitas.

El artista reconocía influencias románicas en la imagen del Cristo de Canillas, en un intento de volver a los orígenes ${ }^{1}$ frente a la denostada imaginería de Olot o Saint-Sulpice, una influencia que estaría presente en toda su obra religiosa. En este sentido, la aportación de Carlos Pascual de Lara fue fundamental en la búsqueda de fuentes de inspiración. Éste importó de Italia la obra de una serie de artistas que, según José Luis Sánchez, estaban realizando una especie de arqueología histórica de la pintura, (...) con un geometrismo y un recuerdo constante del arte románico y del Quattrocento.

Destacaba entre ellos el arcaísmo de Massimo Campigli. La iglesia de Canillas, como otros destacados templos del momento, adelantaba algunos de los criterios que se impusieron tras el Concilio Vaticano II:

El concilio nos dio la razón, pero aquí no lo querían entender, sobre todo el clero secular. Todo esto estaba en el aire. Cada época tiene una especie de maná o de átomos que están en el aire, que van cayendo sobre las cabezas y las van impregnando... Y hay cerebros que están atentos a de dónde viene el maná.

Precisamente, el tema de las imágenes fue uno de los asuntos más polémicos en la introducción del arte contemporáneo en los templos posconciliares. Por un lado, se precisaba fijar el número de imágenes, por otro había que ver si había cabida para el arte no figurativo.

El primer tema era especialmente delicado en España, muy amante de las devociones particulares y donde abundaba la imaginería religiosa en el interior de los templos. Tal fue así que, en referencia a la arquitectura religiosa del momento, se planteó en alguna ocasión la pregunta de si las nuevas iglesias españolas eran protestantes.

\footnotetext{
${ }^{1}$ Recordaba José Luis Sánchez que, con ocasión de una exposición en el Ateneo de Madrid, organizada por él y el padre Aguilar, fueron a presentar la maqueta del catálogo al Nuncio. En éste se alternaban las obras de Lara, Valdivieso, Gabino, Ribera, Oteiza,... con obras tradicionales de arte sacro, principalmente románicas. Al llegar al Cristo de Perpinán, el Nuncio mostró su disgusto y tuvieron que aclararle que se trataba de una talla antigua.
} 
José Luis Sánchez, en una entrevista realizada por ARA en 1966, fijaba el número de imágenes que, a su juicio, debía contener el templo:

Un orden, una jerarquía, se imponen. En primer lugar, Cristo, imagen, signo o símbolo, centrando el culto sobre el altar. Esta presencia determina austeridad, silencio, orden, modestia, una luz, un misterio. Si no basta para expresar la presencia de Cristo un altar desnudo, pongamos una figura insinuada, no torturada, un Crucificado lleno de paz...Luego la figura de María en un lugar de mediación, con la ternura del caso. Cercana al pueblo, asequible, humilde, no rica. Madre de Dios, Madre del pueblo (González Vicario, 1987: 55).

Una imagen del santo titular del templo, colocada en su interior o en el exterior, y un vía crucis completarían la escueta imaginería posconciliar.

También generó polémica la introducción de la abstracción en el arte sacro, asimilable en el caso de las vidrieras, pero difícilmente asumible en el de las imágenes, que cumplían una función devocional. López Quintás matizaba que sería más correcto hablar, en vez de no-figuración, de formas más depuradas.

Como se ha expuesto, la producción de José Luis Sánchez iba encaminada en este sentido.

Cuando se dice que las imágenes de estilo bizantino son abstractas debe advertirse que se trata de una forma de estilización esencializante, que no implica pérdida de contacto con lo real, sino un acercamiento a la verdadera fuente de la realidad (López Quintás, 1965: 6).

Reducido el número de imágenes del templo, los artistas encontraron otro cauce de expresión en el diseño de elementos litúrgicos como altares, ambones, Sagrarios o pilas bautismales.

La segunda colaboración entre Luis Cubillo y José Luis Sánchez fue, en este sentido, ejemplar. El artista diseñó en 1973 toda la obra escultórica de la parroquia de San Fernando, en Madrid. Se trataba del primer templo en el que Cubillo utilizaba la planta cuadrada, disponiendo el presbiterio en uno de sus vértices y adosando la capilla del Santísimo a su derecha.

Previamente había ensayado una planta pentagonal en la parroquia de San Saturnino (1970), en Alcorcón, en su búsqueda de un espacio asambleario que recogiera el espíritu del Concilio. En ambos casos, el arquitecto planteó una 
solución que sólo volvió a repetir, a menor escala, en la iglesia de Santiago, en Guadarrama (1972): la cubierta descendente hacia el altar, con una altura que no superaba los tres metros en la esquina del presbiterio.

En las dos primeras, especialmente en la iglesia de San Fernando, se producía un intenso efecto de concentración hacia el altar, con la apertura de un lucernario sobre él. La comparación de dos edificios nos sirve para valorar la integración de la obra artística en la arquitectura².

Fig. 4-5. Crucificado en la parroquia de San Fernando, Madrid, 1973.
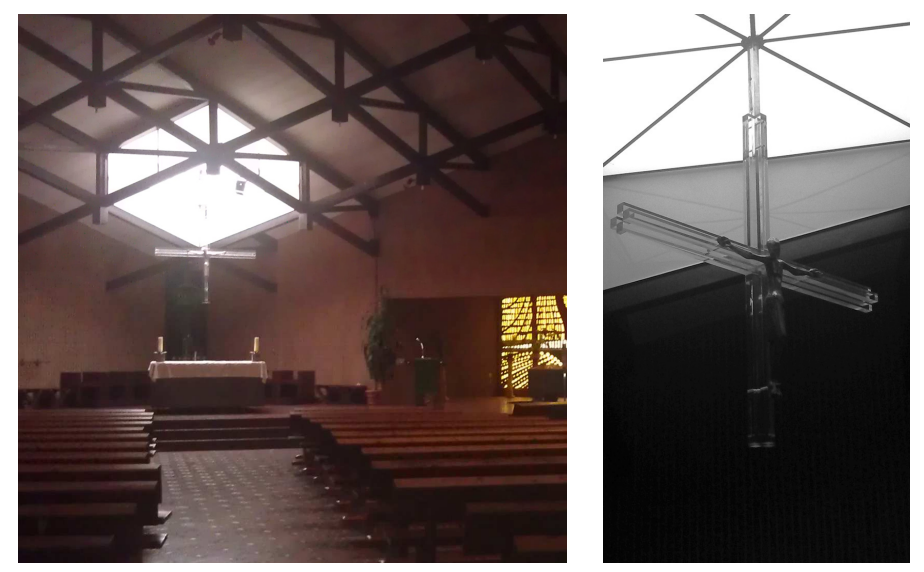

En San Saturnino, el Crucificado de Juan Manuel Martín-Munuera fue realizado en madera de abedul. Medía 1,60 metros de alto y se situaba en una cruz que estaba apoyada en el suelo y que llegaba hasta el techo, constreñida por la singular arquitectura de Cubillo.

Por el contrario, en la iglesia de San Fernando José Luis Sánchez optó por suspender el crucificado del lucernario. La imagen, de reducido tamaño, fue realizada en aluminio.

\footnotetext{
${ }^{2}$ Hay que matizar que la parroquia de San Fernando fue realizada con más medios económicos que la de San Saturnino. Este extremo ha sido confirmado tanto por José Luis Sánchez como por Jacinto Rodríguez Osuna, director en ese momento de la Oficina Técnica del Arzobispado de Madrid. El primero oponía la pobreza de la iglesia de Canillas a los medios con los que se realizó la de San Fernando. El segundo recordaba que en esta parroquia se quiso hacer algo singular dentro de las nuevas iglesias promovidas por el arzobispo Morcillo.
} 
Con sus rasgos apenas insinuados, se dispuso sobre una cruz de metacrilato, material que se usó en otros elementos del edificio.

José Luis Sánchez consiguió imponer en este templo el orden jerárquico que él mismo proponía. Gracias a la elección del metacrilato y su transparencia, la atención de los fieles se centraba primeramente en el altar, bañado por una luz intensa. El crucificado casi no tenía presencia, ni se incidía en su sufrimiento. Más bien, el artista daba prioridad al símbolo de la cruz.

La imagen de la Virgen con el Niño, realizada en aluminio, se situaba en la capilla del Santísimo, en un lugar de mediación entre el altar y el Sagrario. Se ligaba al último mediante un friso de cemento metalizado que se rompía en sus extremos para acogerlos.

Por último, el artista situó una escultura de cemento metalizado de San Fernando en el exterior de la iglesia, próxima a la entrada. No existían más figuras en el templo, cumpliéndose así los preceptos posconciliares: pocas imágenes, correctamente situadas y realizadas en un estilo actual.
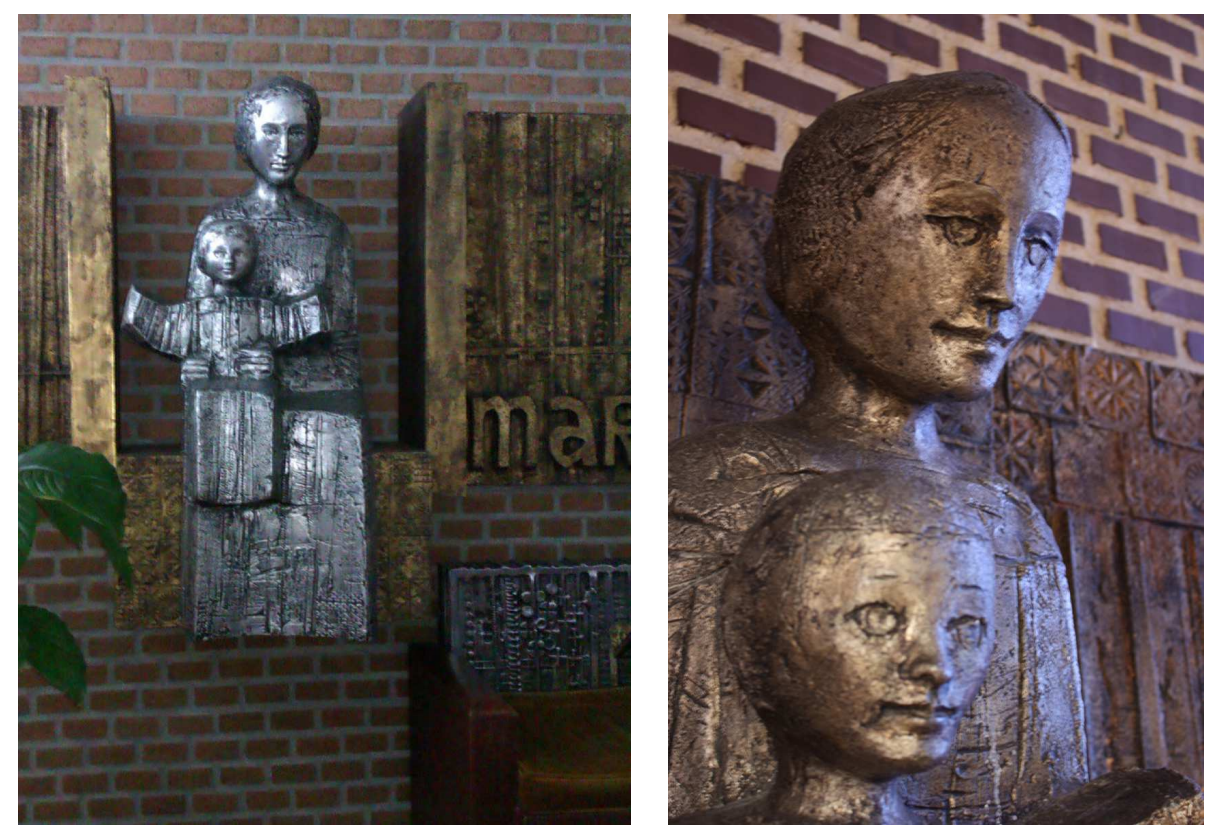

Figs. 6-7. Escultura de Virgen con el niño en la parroquias de San Fernando (1973) y Jesús de Nazaret (1974). 
En el caso de José Luis Sánchez se trataba nuevamente de un hieratismo y una frontalidad herederos del románico que llevaban a una esencialización de las formas. Este rasgo era especialmente evidente en la escultura sedente de la Virgen con el Niño. En ella se eliminaron las manos del segundo, de forma que su cuerpo con los brazos abiertos recordaba el símbolo de la cruz.

La labor del artista en el templo fue mucho más allá de las esculturas realizadas, y llegó hasta el diseño de los manillones de las puertas o los candelabros, ambos de aluminio, o el recipiente del agua bendita situado a la entrada, elaborado a partir de un bloque de metacrilato.

José Luis Sánchez utilizó varias estrategias para lograr que existiera una total armonía entre sus diseños para esta iglesia. Por una parte, en los distintos ámbitos que se crearon en el templo, los materiales que se combinaban eran, a lo sumo, dos. Su elección parecía dictada, en muchos casos, por el tipo de luz que iban a recibir.

Así, en el presbiterio, con luz cenital blanca, el altar era de aluminio y el ambón se realizó combinando aluminio y metacrilato, igual que sucedía en la cruz y la imagen de Cristo que pendían sobre el altar. También la pila bautismal, próxima a ellos, se realizó en aluminio.

Para la capilla del Santísimo, con luz ámbar procedente de ventanas laterales, los materiales elegidos fueron el cemento metalizado en tonos dorados y el aluminio. Con el primero se realizaron el altar y, tras él, el citado friso. En aluminio se hicieron las imágenes de la Virgen y el Niño, el Sagrario, una cruz procesional, el ambón, los candelabros, los aparatos de iluminación, las estaciones del vía crucis y la Sede.

Estas dos últimas se combinaron con madera, material que servía de transición entre el aluminio y las cuidadas paredes de ladrillo visto. Así, en madera se realizaron tanto las butacas que flanqueaban la Sede como las cruces que servían de fondo a las estaciones del vía crucis.

Otra estrategia utilizada en la búsqueda de unidad en el diseño fue la repetición de motivos y formas. Así, las franjas, las cruces, los círculos y las formas aristadas se repitieron en los altares, el ambón, el friso y la pila bautismal. Las estaciones del vía crucis tenían forma de cruz griega, como la de metacrilato 
que pendía sobre el altar. Al igual que ésta, cada brazo se "construía" a partir de la agrupación de cuatro listones de sección cuadrada.
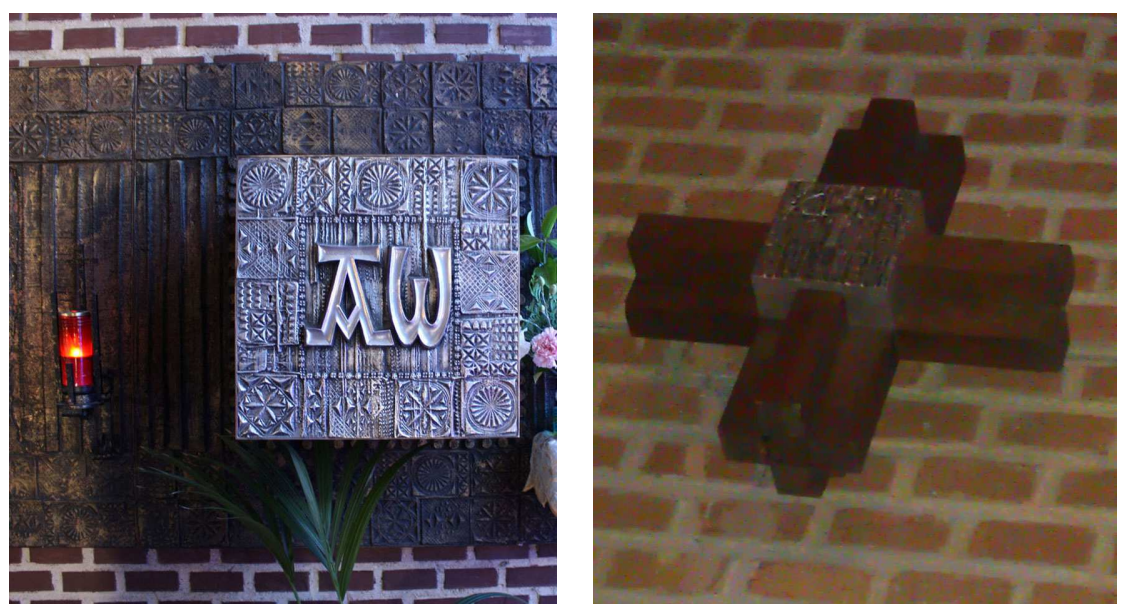

Figs. 8-9. Sagrario de la parroquia de Jesús de Nazaret (1974) y Vía Crucis de la parroquia de San Fernando (1973).

Más sutil era la relación que se daba entre las formas diseñadas por José Luis Sánchez y la arquitectura de Cubillo. Así, el artista recurrió a formas cúbicas o de planta cuadrada, en el altar, la sede o el ambón, haciéndose eco de la geometría que había generado el proyecto. Esta preeminencia de la forma sobre la funcionalidad propició la crítica de la revista ARA, que consideró el ambón "más bello que funcional". ( S.A., 1973: 49)

Por último, el artista también aprovechó el contraste que se daba en los materiales y su tratamiento (liso-rugoso, ligero-pesado, transparente-opaco), para enriquecer su propuesta. Obviamente, la austera arquitectura de ladrillo visto de Cubillo no hacía sino enfatizar el trabajo de José Luis Sánchez.

La última colaboración entre arquitecto y artista se dio en 1974, en la parroquia de Jesús de Nazaret. En ella, José Luis Sánchez diseñó nuevamente toda la obra escultórica, así como los altares y el Sagrario.

En este caso, las imágenes eran tres: una representaba a Jesús de Nazaret y se situaba tras el altar principal. Una Virgen con el Niño, similar a la realizada para San Fernando se ubicaba, como aquélla, en la capilla del Santísimo. 
Por último, el artista realizó una cruz procesional de aluminio con un Cristo de bronce. La estilización de los rostros y los cuerpos, así como la ausencia de dolor o sufrimiento volvían a ser las características dominantes.

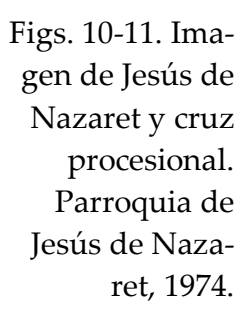

Figs. 10-11. Imagen de Jesús de Nazaret y cruz procesional. Parroquia de Jesús de Nazaret, 1974 .

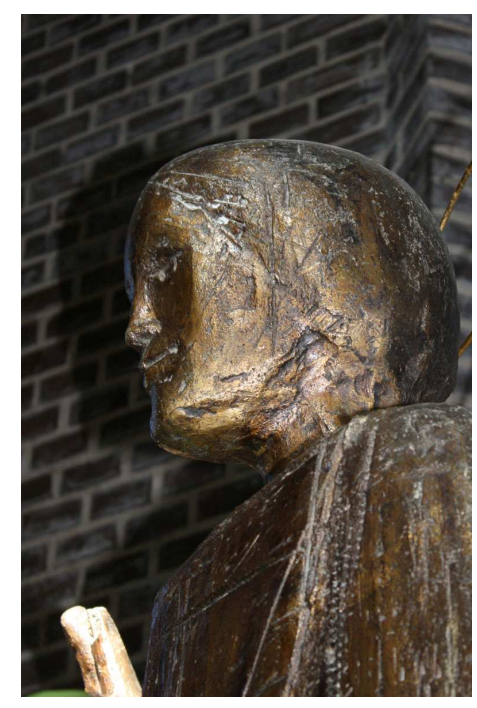

La iglesia pertenecía a una serie de proyectos de parroquias desarrollados por el arquitecto a principios de los años 70, con el templo de planta cuadrada y la capilla del Santísimo adosada a un lateral.

Frente a la singularidad de la solución de San Fernando, Cubillo optó por este modelo, más fácilmente repetible y, seguramente, más económico. Esta reducción presupuestaria era también evidente en el trabajo de José Luis Sánchez, en el que desaparecieron el metacrilato y el aluminio, a excepción del Sagrario y la cruz procesional. El resto se ejecutó en cemento metalizado, realizado en distintos tonos, dorados o plateados.

Esta manipulación de los materiales buscando su máxima expresividad, así como su integración con la arquitectura son características comunes en las obras estudiadas.

Junto a ellas destaca la reducción de la forma a su esencia, a través de la cual José Luis Sánchez tiende un puente entre el románico y la vanguardia del arte sacro del siglo XX. 


\section{Bibliografía.}

AMANN, E. (1965): “Integración de las artes. Una encuesta de Hogar y Arquitectura", Hogar y Arquitectura, 58, I-V.

BlANCO AGÜEIRA, S. (2011): "El misterio entre pliegues y hendiduras. Entrevista con el escultor José Luis Sánchez", Boletín Académico. Revista de investigación y arquitectura contemporánea Escuela Técnica Superior de Arquitectura. Universidade da Coruña, 1, págs. 73-79.

Centellas Soler, M. (2010): Los pueblos de colonización de Fernández del Amo. Arte, arquitectura y urbanismo, Fundación Caja de Arquitectos, Barcelona, págs. 213-253.

GONZÁLEZ VICARIO, M. T. (1985): “José Luis Sánchez: su escultura religiosa en templos madrileños", Villa de Madrid, 83, págs. 56-58.

GONZÁLEZ VICARIO, M. T. (1987): Aproximación a la escultura religiosa contemporánea en Madrid, Universidad Nacional de Educación a Distancia, Madrid.

LÓPEZ QUINTÁS, A. (1973): “El dilema figuración-abstracción”, Arquitectura, 73 (enero), págs. 3-13 s.a.

LÓPEZ QUINTÁS, A. (1973): "San Fernando. Complejo parroquial-Madrid", ARA. Arte Religioso Actual, 36 (abril-mayo), págs. 44-49.

SÁNCHEZ, J. L. (1981): José Luis Sánchez: casi treinta años de oficio de escultor: Palacio de Cristal del Parque del Retiro de Madrid, marzo-abril 1981, Ministerio de Cultura, Dirección General de Bellas Artes, Archivos y Bibliotecas, Madrid. TrApIELlO, A. (1976): José Luis Sánchez: el rescate de los signos, Rayuela, Madrid.

\section{Fuentes documentales.}

Legado Luis Cubillo de Arteaga (LCA), depositado en el Servicio Histórico de la Fundación COAM. Archivo del Arzobispado de Madrid.

Otras fuentes.

Entrevista realizada al artista José Luis Sánchez el 22 de diciembre de 2011 en Pozuelo de Alarcón (Madrid). 